\title{
Time Performance of Digital Video Watermarking with MATLAB
}

\author{
Gyanendra Tomar \\ M. Tech Scholar, IET Alwar \\ Computer Science Engineering \\ Department
}

\author{
Deepak Chaudhary \\ Assistant Professor, IET Alwar \\ Computer Science Engineering \\ Department
}

\author{
Vikas Chandra Sharma \\ Assistant Professor \\ Dr MPS Memorial College of \\ Business Studies Agra
}

\begin{abstract}
A new framework is established for time-based synchronization in sightless symmetric video watermarking. Embedding and detection models are planned that include the conduct of many video watermarking methods. These representations establish that synchronization is stimulating when the waterline lacks dismissal, but also that wellorganized synchronization can be attained by scheming the transformation. The transformation models are modified to spatial synchronization in still image watermarks. For wavelets transformation calculate the execution time and then compare the result with different transformation.
\end{abstract}

\section{Keywords}

Watermarking, transformation, wavelets

\section{INTRODUCTION}

The use of digital video has full-fledged melodramatically in latest times. Digital video presentations include videoconferencing, video-on-demand, digital television, digital cinema, distance learning, entertainment, surveillance, and advertising. Many users practise digital video when they watch a motion picture recorded on a digital video disc (DVD) or downloaded over the Internet. The propagation of digital video into more applications is heartened by educating compression skill, better authoring and editing tools, lowercost capture and display devices, and more obtainable bandwidth in digital communication networks.

Digital picture offers much compensation for processing and allocating video and other types of information. First, digital software programs offer unparalleled suppleness in creating, editing, presenting, and deploying the digital information. Analog devices deficiency the flexibility, malleability, and extensibility of software processing. Second, digital communications networks (such as the Internet) allow digital data to be scattered and circulated on a wide scale. On some of these networks, existing open and branded procedures such as the WorldWideWeb allow any user to effortlessly and reasonably obtain, provide, conversation, and find digital information. Lastly, digital information can be treated, and in particular, copied without presenting loss, degradation, or noise [1]. For example, an unlimited number of faultless copies can be shaped from a single digital video signal..

\section{APPLICATIONS OF WATERMARING}

While content protection (including content tracking) has frequently been stated as the incentive for digital watermarking, watermarking can be used in other applications as well. Applications and potential applications of watermarking include [2, 28, 34-37]:
- Content Tracking: The holder personalizes each copy of the content by embedding a watermark into the copy. The embedded watermark classifies the user who has keeping of that copy. Any following digital copies made of the watermarked satisfied will also be watermarked. If a doubtful copy of the content is exposed, detecting the watermark discloses the source of the suspect copy. These watermarks are sometimes mentioned to as fingerprints

- Owner or Copyright Identification: In copyright watermarking, the embedded watermark encodes ownership information such as the individuality of the owner and the copyright date. Noticing the watermark delivers the gratified owner with supplementary indication of possession in the event of a argument. The embedded information may also be valuable in detecting or showing copy, particularly when the watermark is perceived in supposedly original satisfied from a third party.

- Copy Protection: The attendance of the watermark classifies the watermarked content as copy protected. A device that follows the copy protection procedure detects the watermark and then prohibits the creation of copies. Some copy protection systems allow the user to create a single generational copy but limit the user from making supplementary copies from a copy [3]. In such arrangements, an embedded watermark could encode information such as "always allow additional copies", "only one additional copy allowed", and "no more copies allowed". Using watermarks in this method needs collaboration from footage devices to notice the watermark and prevent unsanctioned copying.

Broadcast Monitoring [4]: An embedded watermark may be used to identify or identify a signal of interest, predominantly when the signal has been intertwined or compound with other signals. Recognition happens when the watermark is noticed. For example, an publicist needs to verify that a specific advertisement is being transmission as contracted. Verification and auditing are important thoughts when the manufacture and delivery of broadcast video content, including announcements, entertaining content, and news, have enormous economic value.

- Authentication: The capability to perceive changed or fake video is dangerous in applications such as video surveillance [5-6]. An embedded watermark encrypts information necessary to confirm the truthfulness of the watermarked signal [7-10].

"Smart" Content [11]: An embedded watermark can be used in conjunction with devices to provide additional functionalities or services that benefit the user. For example, 
the watermark embedded in a music video may describe a link to the artist's Internet site which allows a user to purchase the artist's (other) works.

- Robust Data Hiding or Steganography [12]: The embedded watermark may be used as a covert channel to communicate messages from one user to another.

For example, the sender embeds the watermark into a video, encoding the secret message in the watermark. The watermarked video is then provided to the recipient(s), possibly by using an insecure channel or by making the video publicly available.

\section{WAVELET APPLICATIONS}

Wavelets can be used in different areas or with different application.

- Detecting Discontinuities and Breakdown Points (I and II)

- Detecting Long-Term Evolution

- Detecting Self-Similarity

- Identifying Pure Frequencies

- $\quad$ Suppressing Signals

- De-Noising Signals

- Compressing Signals

The projected algorithm is executed for each of the below wavelets. wavemngr('read',1)

ans $=$

\begin{tabular}{|c|c|c|c|}
\hline \multirow{2}{*}{\multicolumn{2}{|c|}{$\begin{array}{l}\text { Haar } \\
========= \\
\text { Daubechies }\end{array}$}} & \multicolumn{2}{|l|}{ haar } \\
\hline & & & $\mathrm{db}$ \\
\hline $\mathrm{db} 1$ & $\mathrm{db} 2$ & $\mathrm{db} 3$ & $\mathrm{db} 4$ \\
\hline db5 & db6 & $\mathrm{db} 7$ & $\mathrm{db} 8$ \\
\hline db9 & $\mathrm{db} 10$ & $\mathrm{db}^{* *}$ & \\
\hline Symlets & & sym & \\
\hline sym2 & sym3 & sym4 & sym5 \\
\hline sym6 & sym7 & sym8 & $\operatorname{sym}^{* *}$ \\
\hline Coiflets & & coif & \\
\hline $\begin{array}{l}\text { coif1 } \\
\text { coif5 }\end{array}$ & coif2 & coif3 & coif4 \\
\hline
\end{tabular}

\begin{tabular}{|c|c|c|c|}
\hline \multicolumn{3}{|c|}{ BiorSplines } & \multirow{2}{*}{$\begin{array}{l}\text { bior } \\
\text { bior2.2 }\end{array}$} \\
\hline bior1.1 & bior1.3 & bior1.5 & \\
\hline bior2.4 & bior2.6 & bior 2.8 & bior3.1 \\
\hline bior3.3 & bior3.5 & bior3.7 & bior3.9 \\
\hline bior4.4 & bior5.5 & bior6.8 & \\
\hline \multicolumn{3}{|c|}{ ReverseBior } & rbio \\
\hline rbio1.1 & rbio1.3 & rbio1.5 & rbio2.2 \\
\hline rbio2.4 & rbio2.6 & rbio2.8 & rbio3.1 \\
\hline rbio3.3 & rbio3.5 & rbio3.7 & rbio3.9 \\
\hline rbio4.4 & rbio5.5 & rbio6.8 & \\
\hline
\end{tabular}

Meyer meyr

\begin{tabular}{|c|c|c|}
\hline $\begin{array}{l}\text { DMeyer } \\
============\end{array}$ & $\begin{array}{l}\text { dmey } \\
=====\end{array}$ & $=============$ \\
\hline Gaussian & & gaus \\
\hline $\begin{array}{ll}\text { gaus1 } & \text { gaus2 } \\
\text { gaus5 } & \text { gaus6 } \\
\text { gaus** } & \end{array}$ & $\begin{array}{l}\text { gaus3 } \\
\text { gaus7 }\end{array}$ & $\begin{array}{l}\text { gaus4 } \\
\text { gaus8 }\end{array}$ \\
\hline $\begin{array}{l}\text { Mexican_hat } \\
===========\end{array}$ & $====$ & $\begin{array}{l}\text { mexh } \\
============\end{array}$ \\
\hline Morlet & morl & \\
\hline Complex Gaussiar & & cgau \\
\hline $\begin{array}{l}\text { cgau2 } \\
\text { cgau** }\end{array}$ & cgau3 & cgau4 \\
\hline
\end{tabular}

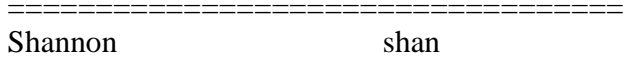

shan1-1.5 shan1-1 shan1-0.5 $\operatorname{shan} 1-0.1$

shan $2-3$ shan**

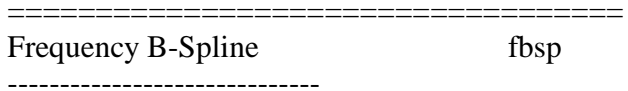

$\begin{array}{ll}\text { fbsp1-1-1.5 } & \text { fbsp1-1-1 fbsp1-1-0.5 } \\ \text { fbsp2-1-0.5 } & \text { fbsp2-1-0.1 fbsp** } \\ \text { =============================== }\end{array}$

\begin{tabular}{|c|c|}
\hline Complex Morlet & cmor \\
\hline $\begin{array}{l}\text { cmor } 1-1.5 \\
\text { cmor } 1-0.5\end{array}$ & $\begin{array}{l}\text { cmor1-1 cmor1-0.5 } \\
\text { cmor1-0.1 cmor** }\end{array}$ \\
\hline
\end{tabular}

\section{WORKFLOW/WATERMARK EMBEDDING ALGORITHM}

Step 1: Loading Video from hard disk using VideoReader function

Step2: read the secret image from hard disk.

Step 3: Divided the video into the frame.

Step 4: Create Structure array for frame.

Step 5: Apply the conversion colour model and Convert from RGB to YUV image.

Step 6: Take input frame with secret image to apply discrete wavelets transformation.

Step 7: Embedding the secret image into the each frame of video.

Step 8: Convert embedded frame back into RGB

Step 9: Display frame successfully.

\section{WATERMARK EXTRACTION ALGORITHM}

The extraction procedure involves extracting the watermark from the host video in which it was embedded. Various steps are involved which are as mentioned below.

Step1: Read the watermarked video and split it into frames.

Step 2: Take watermarked frame along with original frame.

Step 3: Apply dwt2 at level 1 for watermarked image.

Step 4: Again Apply dwt2 at level 2 for watermarked image.

Step 5: Apply dwt2 at level 1 for original image. 
Step 6 Again Apply dwt2 at level 2 for original image.

Step 7: Apply extraction algorithm for extraction the secret image.

Step 8: Displays the original video, watermarked video and secret image.

\section{RESULT AND IMPLEMENTATION}

Software Model: The first and the most important part in this process is the software model. The software model uses the image processing technology. The programs are implemented in MATLAB.

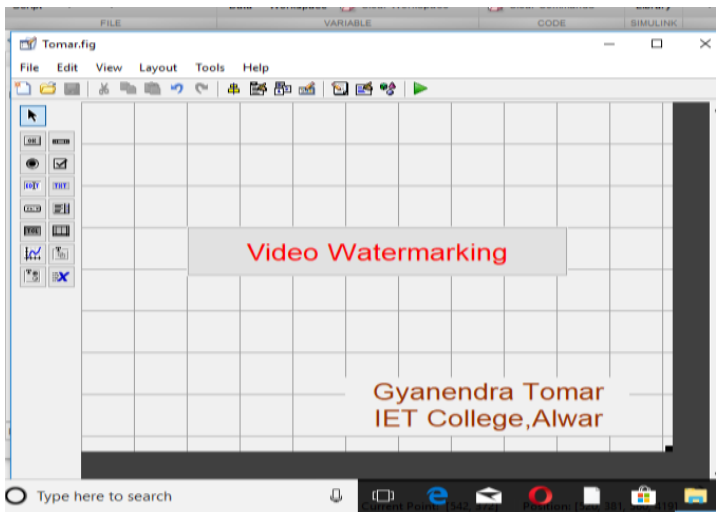

Figure 1: Software Model

In Software model click on video watermarking button, proposed algorithm would be run, record the elapsed time for loading, embedded and extraction for different supported wavelets.

The input colored video and watermark image is shown below:

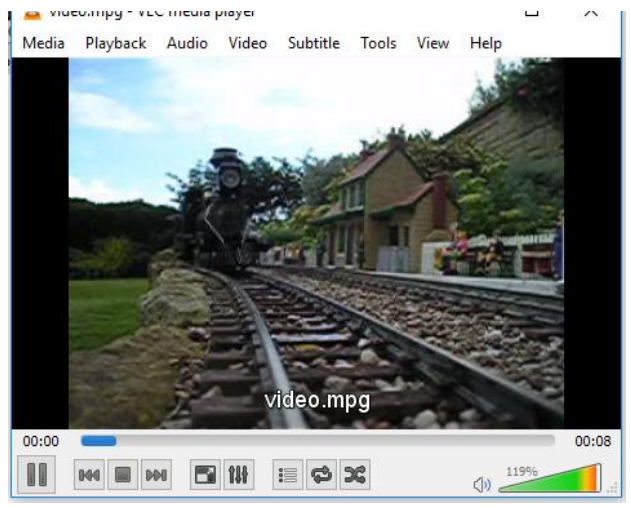

Figure 2: Host Video

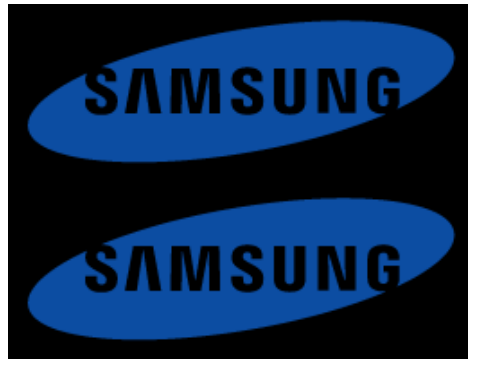

Figure 3: Original Watermark Image

Some of the output results are shown below:

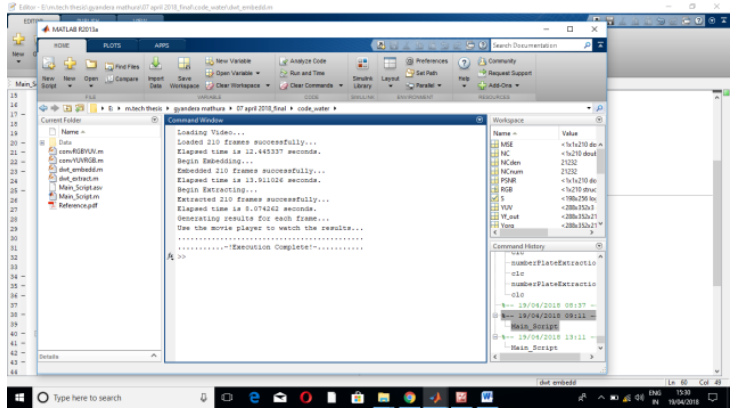

Fig 4: Result of Bior 1.1

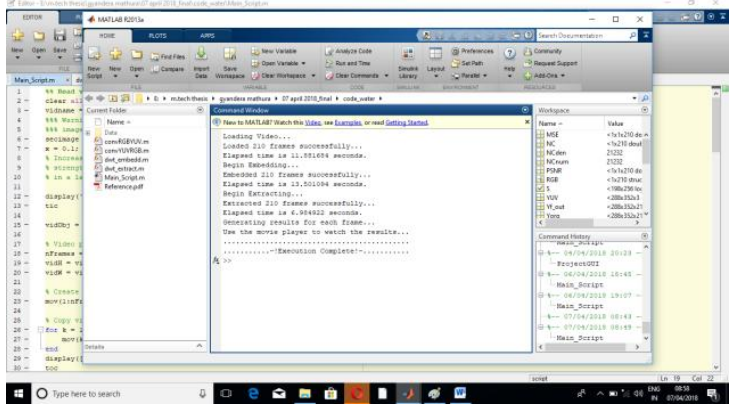

Fig 5: Result of db1

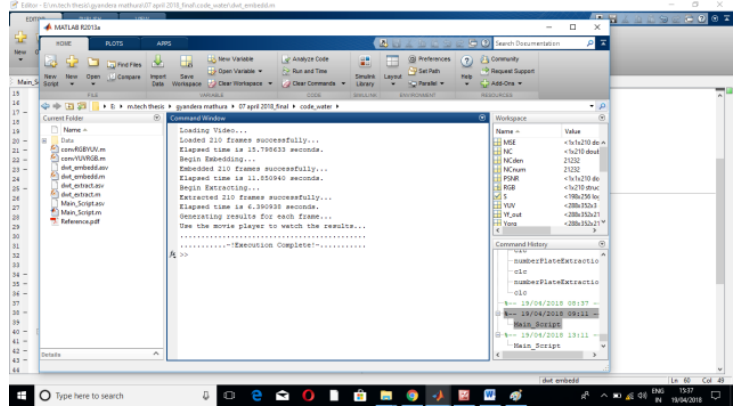

Figure 6: Result of rbio1.1

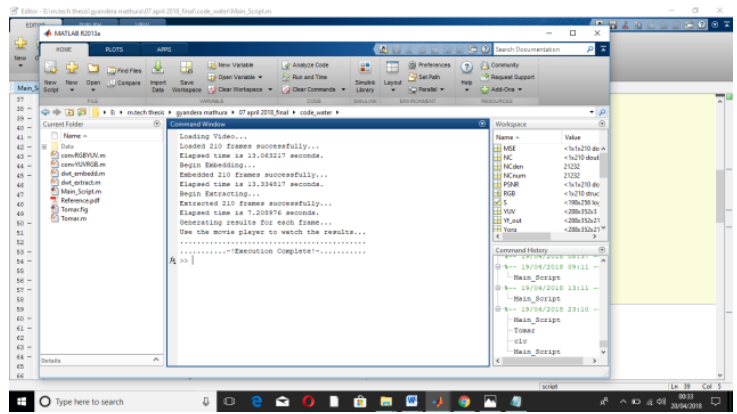

Figure7: Result of sym1

\section{EXECUTION TIME}

The adeptness of a program depends upon two factors:

1. Space.

2. Time.

In the recent computer technologies, there is a lot of space available and hence a programmer is permitted from space chores. So the central factor which chooses whether the specific procedure is best or efficient to accomplish confident task be contingent on its execution time. We can define 
execution time as time in which a particular algorithm generates output.

The execution time of a given procedures is equal to the time spent by the handled procedures from entry point to exit. In below table time recorded in sec.

Table 1: Time Comparison with Wavelets

\begin{tabular}{|l|l|l|l|}
\hline Wavelets/Stage & Loading, & Embedded & Extraction \\
\hline Bior1.1 & 12.445337 & 13.911026 & 8.074262 \\
\hline Db1 & 11.881684 & 13.501094 & 6.984922 \\
\hline Rbio1.1 & 15.798633 & 11.850940 & 6.390938 \\
\hline Sym1 & 13.063217 & 13.334817 & 7.208976 \\
\hline
\end{tabular}

\section{CONCLUSION}

The proposed method for a new digital watermarking technique through wavelets technology was explained It can be concluded that taking into consideration a proposed algorithm. Wavelets $\mathrm{db} 1$ is fast or better than other supported wavelets with respect to the execution time for loading, embedded and extraction.

\section{REFERENCES}

[1] A. M. Eskicioglu and E. J. Delp, "An overview of multimedia content protection in consumer electronics devices," Signal Processing: Image Communication,vol. 16, no. 7, pp. 681-699, Apr. 2001.

[2] E. T. Lin, A. M. Eskicioglu, R. L. Lagendijk, and E. J. Delp, "Advances in digital video content protection," Proceedings of the IEEE: Special Issue on Advances in Video Coding and Delivery, vol. 93, no. 1, pp. 171-183, Jan. 2005.

[3] J. A. Bloom, I. J. Cox, T. Kalker, J.-P. M. G. Linnartz, M. L. Miller, and C. B. S. Traw, "Copy protection for dvd video," Proceedings of the IEEE, vol. 87, no. 7, pp. 1267-1276, July 1999.

[4] T. Kalker, G. Depovere, J. Haitsma, and M. Maes, "A video watermarking system for broadcast monitoring,"
Proceedings of the SPIE Security and Watermarking of Multimedia Contents, vol. 3657, San Jose, CA, Jan. 2527, 1999,pp. 103-112.

[5] F. Bartolini, A. Tefas, M. Barni, and I. Pitas, "Image authentication techniquesfor surveillance applications," Proceedings of the IEEE, vol. 89, no. 10, pp.1403-1418, Oct. 2001

[6] G. Friedman, "The trustworthy digital camera: Restoring credibility to the photographic image," IEEE Transactions on Consumer Electronics, vol. 39, pp. 905910, Nov. 1993.

[7] P. W. Wong and N. Memon, "Secret and public key image watermarking schemes for image authentication and ownership verification," IEEE Transactions on Image Processing, vol. 10, no. 10, pp. 1593-1601, Oct. 2001.

[8] M. U. Celik, G. Sharma, E. Saber, and A. M. Tekalp, "Hierarchical watermarking for secure image authentication with localization," IEEE Transactions on Image Processing, vol. 11, no. 6, pp. 585-595, June 2002

[9] E. T. Lin, C. I. Podilchuk, and E. J. Delp, "Detection of image alterations using semi-fragile watermarks," Proceedings of the SPIE Security and Watermarking of Multimedia Contents II, vol. 3971, San Jose, CA, Jan. 23-28, 2000, pp. 152-163.

[10] E. T. Lin and E. J. Delp, "A review of fragile image watermarks," Proceedings of the Multimedia and Security Workshop at ACM Multimedia '99, Orlando, FL, Oct. 30-31, 1999, pp. 25-29.

[11] A. M. Alattar, ““'Smart images” using Digimarc's watermarking technology," Proceedings of the SPIE Security and Watermarking of Multimedia Contents II, vol. 3971, San Jose, CA, Jan. 24-26, 2000, pp. 264-273.

[12] S. Katzenbeisser and F. A. P. Petitcolas, Eds. Information Hiding: Techniques for Steganography and Digital Watermarking. Norwood, MA: Artech House, 2000. 